\title{
A criança e a apropriação da linguagem escrita na perspectiva Histórico-Cultural: o que os professores precisam saber/conhecer desse processo?
}

\section{The child in the appropriation of written language in the Historical-Cultural perspective: what teachers need to know/know about this process?}

\author{
Hercília Maria de Moura Vituriano1 ${ }^{1 *}$, Inara Sydia dos Santos Dourado212, Raimundo Simas \\ Abreu Neto3 ${ }^{13}$
}

\begin{abstract}
RESUMO
O trabalho objetiva refletir sobre o processo de apropriação da Linguagem Escrita por parte da criança na Educação Infantil partindo dos pressupostos da Teoria Histórico-Cultural, com vista à construção de perspectivas teórico-metodológicas para subsidiar o trabalho docente nessa etapa da Educação Básica. A questão norteadora é: Quais pressupostos da teoria Histórico-Cultural podem contribuir para situar os saberes/conhecimentos necessários aos professores sobre o processo de apropriação da Linguagem Escrita na Educação Infantil? A pesquisa é bibliográfica, fundamentada em Bakhtin (1986); Vygotsky (2007); Leontiev (1978) e Luria (2001), para compreensão dos processos de aprendizagem e desenvolvimento humano, em relação à criança pequena; Geraldi (2011), Smolka (2012) e Mello (2016), organização das práticas pedagógicas; Tardif (2014) e Gauthier (2012), saberes/conhecimentos necessários à docência. Constatamos que as questões contribuem para orientar o trabalho pedagógico na Educação Infantil com a linguagem escrita, situando as concepções de criança, de aprendizagem e desenvolvimento. Tais concepções são as bases das escolhas teórico-metodológicas em sala de aula.
\end{abstract}

Pal avras-chave: Educação Infantil; Teoria Histórico-Cultural; Linguagem Escrita.

\begin{abstract}
The work aims to reflect on the process of appropriation of Written Language by the child in Early Childhood Education based on the assumptions of the Historical-Cultural Theory, with a view to building theoretical and methodological perspectives to support the teaching work in this stage of Basic Education. Guiding question: Which assumptions of Historical-Cultural theory can contribute to situate the knowledge/knowledge needed by teachers about the process of appropriation of Written Language in Early Childhood Education? The research is bibliographical, based on Bakhtin (1986); Vygotsky (2007); Leontiev (1978) and Luria (2001), for understanding the processes of learning and human development, in relation to young children; Geraldi (2011), Smolka (2012) and Mello (2016), organization of pedagogical practices; Tardif (2014) and Gauthier (2012), knowledge/knowledge necessary for teaching. We found that the questions contribute to guide the pedagogical work in Early Childhood Education with the written language, situating the conceptions of children, learning and development. Such conceptions are the basis of theoretical-methodological choices in the classroom.
\end{abstract}

Keywords: Child education; Historical-Cultural Theory; Written language.

\footnotetext{
1 Doutora em Educação. Professora Adjunta no Departamento de Educação I e do Programa de PósGraduação em Gestão de Ensino da Educação BásicaPPGEEB/UFMA.1. *E-mail: hercilia.maria@ufma.br

2 Pedagoga e Mestranda do PPGEEB/UFMA.

${ }^{3}$ Pedagogo e Mestrando do PPGEEB/UFMA.
} 


\section{INTRODUÇÃO}

Sem sombra de dúvidas, nos últimos anos, ocorreram inúmeras produções acadêmicas sobre o processo de apropriação da linguagem escrita na Educação Infantil. Essas produções nos desafiam a pensar sobre perspectivas para a organização do trabalho docente com as crianças nessa área. No momento atual em que vivenciamos os desafios impostos por parte da pandemia de Covid-19, muitas análises precisam continuar sendo feitas em função das dificuldades a esta realidade, aliadas àquelas com as quais os profissionais da Educação Infantil já vivenciavam em sua realidade profissional frente ao trabalho com a linguagem escrita. Um exemplo disso são as problemáticas que emergem a partir de produções que defendem atividades nessa área valorizando, apenas, os aspectos formais da língua, com práticas destituídas de sentido para as crianças.

Um pressuposto importante que os professores da Educação Infantil não devem perder de vista, quer estejam em contexto de pandemia ou não, é situar as concepções de criança, aprendizagem e desenvolvimento e de linguagem escrita. Esse processo contribui para que possam justificar suas escolhas teórico-metodológicas de forma consciente. São essas concepções que embasam, em grande medida, o trabalho docente (LIMA; SILVA; RIBEIRO, 2010).

Sabemos que algumas incertezas ainda se fazem presentes nesse momento de pandemia, entretanto, é importante não perder de vista algumas conquistas teóricas e metodológicas, construídas sobre a linguagem escrita na Educação Infantil, especialmente aquelas que, concebem a linguagem como, processo de interação. Assim, nesse trabalho abordamos essa temática a partir dos pressupostos da teoria HistóricoCultural, com ênfase nas teorizações de Vygotsky e colaboradores, que compreendem a criança como sujeito da aprendizagem, capaz de aprender sempre, por meio de interações humanas, portanto, humanizadoras. Nesse processo, evidencia-se um novo olhar sobre a Educação Infantil como afirma Lima, Silva e Ribeiro (2010, p. 16).

Decorrente desse novo olhar sobre a criança, surge, também, uma nova significação para a educação infantil como possibilidade de humanização, oriunda de processos intencionais e conscientes de ensino e de aprendizagem das crianças a partir do seu nascimento.

Nesse sentido compreendemos que a teoria Histórico-Cultural e alguns de seus fundamentos podem favorecer a construção de caminhos metodológicos para situar o 
trabalho docente de professores da Educação Infantil com a linguagem escrita. Dentre essas contribuições destacamos as problematizações feitas em relação àquelas situações de ensino que valorizam práticas pedagógicas, exclusivamente, centradas no traçado de letras, na sonorização do alfabeto, ou seja, nos aspectos estruturais da língua. Com isso a função social desse objeto cultural é totalmente desconsiderada. Tais práticas desfavorecem o processo de atribuição de sentido à linguagem escrita, por parte da criança. Portanto entedemos que uma das possibilidades de enfretnamento a essas práticas e de sua resignifcação pode, ocorrer a partir de uma processo formative no qual os professores da primiera infância possam acessar conhecimntos teoricos-práticos que promovam uma refelxão critica sobre a prática docente. Nossa perecepão é de que a teoria Histórico-Cultural, é uma dessas possibilidades de resignifcação, especialmente, a partir das teorizações de Vygotsky e colaboradores sobre a criança, a aprendizagem e desenvolvimento e, por sua vez, da lingugaem escrita.

Defendemos que a linguagem escrita deve ser abordada no contexto da Educação Infantil considerando seus usos sociais e o texto como unidade básica de organização do trabalho pedagógico e não o treino de letras e palavras isoladas. Essa posição será aprofundada, em outro tópico nesse trabalho. Ainda sobre a questão da importância de conceber a linguagem escrita em contexto social, Vygotsky (1995) já refletia na década de 20 do século passado, que ao valorizarmos excessivamente atividades que enfocam no aspecto técnico da língua, retirando da criança a oportunidade de aprender, atribuindo sentido e significado a este objeto cultural, dificultamos o seu processo de aprendizagem e desenvolvimento. O autor defende ainda que é preciso definir uma unidade mínima para ensinar a escrita, ou seja, definir um ponto de partida. Nessa busca defendeu que a unidade mínima é constituída por uma unidade de significado. Assim, entendemos que não será por meio da apresentação de letras isoladas que se aprende significativamente. Na verdade, é a enunciação, ou seja, o texto em contexto, que contribuirá para o aprendizado real. Como afirma Melo (2012, p. 76) é “[...] um texto, o que envolve a objetivação de uma ideia, de uma experiência, de uma informação, enfim, de um desejo de expressão."

Dessa forma, é importante destacar que, a posição teórica, assumida neste trabalho não pretende apresentá-la como sendo a única e verdadeira perspectiva, mas diante de nossas experiências e estudos na área temos construído uma percepção de que a produção teórica, Histórico-Cultural fornece elementos fundamentais para constituição de uma prática docente alinhada às necessidades das crianças da Educação Infantil, no que se 
refere ao processo de apropriação da linguagem escrita. Essa base teórica amplia os horizontes de forma consistente, especialmente, sobre os modos de aprendizagem e, desenvolvimento da criança. Mello (2010a), evidencia uma questão importante a partir das teorizações de Vygotsky, ao destacar a necessidade de expressão das crianças, de como a linguagem escrita situada, contribui para esse processo.

Quando cultivamos nas crianças o desejo de expressão, quando criamos nelas a necessidade da escrita e quando utilizamos a escrita considerando sempre sua função social, estaremos respondendo ao apelo de Vygotsky para que os educadores ensinem às crianças a linguagem escrita e não as letras. (MELLO, 2010a, p. 184).

Contribuir para que os professores da Educação Infantil possam situar o seu trabalho do ponto de vista teórico e metodológico é um grande desafio. E ao mencionar essa preocupação com os professores da infância, sabemos das inúmeras questões que precisam de problematização, especialmente, sobre seus saberes/conhecimentos e práticas docents. Problematizar a partir de questões históricas acerca da compreensão do processo de aprendizagem e desenvolvimento, relacionados à linguagem escrita. Revisitar concepções que se cristalizaram no âmbito das instituições de Educação Infantil como possibilidade de reinventar o processo de ensino e aprendizagem.

Nesse processo de resignifcação das práticas docentes na primeira infância, tornase fundamental analisar, ainda os sentidos atribuídos aos saberes/conhecimentos de um profissional dessa etapa da educação. É uma problemática que precisa ser estudada e refletida com esses profissionais, tendo em vista que o trabalho docente na Educação Infantil, em algumas situações, é relacionado a uma mera ação cotidiana ligada ao cuidado materno. Arce (2001) compreende essa questão quando reflete sobre as imagens sociais atribuídas à docência na Educação Infantil. A autora evidencia o problema relacionado ao "mito" da maternidade, da vocação, da mulher como "educadora nata".

Questões que trazem implicações para situar a docência como profissãoe, por sua vez, os saberes/conhecimentos necessários nesse contexto: Basta mesmo ter um sentimento maternal e mobilizar a experiência de ser mãe para ensinar as crianças pequenas? E em relação ao trabalho com a linguagem escrita, como organizar a prática educativa a partir das contribuições de Vygotsky no contexto da Educação Infantil? Essas questões podem contribuir para uma análise sobre os saberes/conhecimentos mobilizados nesse contexto da primeira infância, com a linguagem escrita. 
Diante das questões suscitadas o trabalho em tela, assume o seguinte objetivo: refletir sobre o processo de apropriação da linguagem escrita por parte da criança na Educação Infantil a partir dos pressupostos da teoria Histórico-Cultural, com vista à construção de perspectivas teórico-metodológicas para subsidiar o trabalho docente nessa etapa da Educação Básica. Definido o objetivo partimos para a próxima etapa do trabalho buscando respostas ou subsídios que possam ajudar a desvelar a seguinte questão problematizadora: Quais conhecimentos/saberes podem contribuir para a organização do trabalho dos professores da Educação Infantil em relação ao processo de apropriação da linguagem escrita a partir dos pressupostos da teoria Histórico-Cultural?

A partir dessas definições, os pressupostos metodológicos do trabalho estão alicerçados na abordagem qualitativa. A pesquisa é do tipo bibliográfica, a qual é compreendida como processo que envolve a ampliação de conhecimentos construídos acerca de um dado objeto. Ou seja, "não é mera repetição do que já foi dito ou escrito sobre certo assunto [...]” (Marconi e Lakatos, 2010, p. 166), afinal sempre é possível inovar nas análises sobre um mesmo tema, a depender da forma de abordagem. Este é o nosso desafio.

Assim, os referenciais base de análise são os trabalhos de Bakhtin (1986), o qual se insere no contexto dos estudos da teoria Histórico-Cultural sobre linguagem e ainda de Vygotsky (1995, 1996, 2000, 2007), Leontiev (1978) e Luria (2001) para compreensão dos processos de aprendizagem e desenvolvimento humano da criança. Ampliamos essa discussão para a questão da organização das práticas pedagógicas, a partir das contribuições de Mello (2005, 2010, 2016), Geraldi (2011) e Smolka (2012) entre outros. Os trabalhos de Tardif $(2002,2014)$ e Gauthier (2012) servirão de base para analisar os saberes dos professores da primeira infância no que se refere à apropriação de saberes/conhecimentos necessários à docência.

\section{PRESSUPOSTOS PARA UMA DOCÊNCIA SITUADA NA EDUCAÇÃO INFANTIL: SABERES/CONHECIMENTOS SOBRE LINGUAGEM ESCRITA}

Centraremos nossas analyses, nesse momento do trabalho, em duas questões, a saber: evidenciar pressupostos teóricos para compreender o processo de apropriação da linguagem escrita na Educação Infantil e, por sua vez, elucidar a base de conhecimentos/saberes que os professores precisam acessar para subsidiar sua prática atuando de forma consciente e consistente. Assim, por que relacionar os saberes docentes 
a um trabalho pedagógico que envolve a linguagem escrita na Educação Infantil? Entendemos que nos espaços de Educação Infantil, falar de leitura e escrita ainda gera polêmicas e conflitos. Em geral os debates envolvem um pseudo-dilema: "alfabetizar" ou "não alfabetizar" as crianças pequenas, ou ainda, ensinar a língua em seus aspectos formais, ou apenas introduzir algumas noções sobre sua organização. A concepção defendida neste artigo vai além dessa polarização, assumindo a defesa de que é preciso garantir o direito das crianças à imersão em práticas sociais com a Linguagem Escrita, sem contraposição, ao direito que têm de serem criança e de acessar a cultura elaborada.

Ao partir da compreensão de que os professores precisam de bases teóricas consistentes para atuar de forma consciente. Esse reconhecimento da importância de uma base de conhecimentos para a prática docente refletida e crítica, contribui para a constituição da docência como uma profissão, feita de saberes/conhecimentos próprios. Para nos ajudar a compreender sobre a importância de continuarmos aprendendo sobre a criança e em relação, a sua apropriação em relação a linguagem escrita, Mello (2010a, p. 181) esclarece que:

Podemos buscar maneiras de melhorar o que estamos fazendo e a maneira como trabalhamos para garantir isso que todos queremos e que é a maior conquista que a educação pode permitir: a formação e o desenvolvimento máximo da inteligência e da personalidade das crianças. A apropriação da escrita como um instrumento cultural complexo é elemento essencial na formação da inteligência de cada sujeito.

Como os professores podem melhorar o que estão fazendo, sem uma base teórica que possa promover uma prática situada? Falar de melhorar o que se faz é dar as condições para que os docentes possam refletir sobre o que estão fazendo. Nessa perspectiva, defender que os professores possam acessar teorias que contribuam com suas práticas é possibilitar que acessem uma das condições para uma atuação profissional. Nesse sentido, a discussão sobre os saberes docentes, nesse trabalho é fundamental. Esclarecer em alguma medida os saberes/conhecimentos sobre a criança, aprendizagem e desenvolvimento e, sobre a linguagem escrita é uma parte importante daquilo que um professor precisa compreender para uma prática consciente.

De acordo com Tardif e Lessard (2014), o trabalho docente precisa ser abordado de dois ângulos importantes, a saber: do ponto de vista de sua organização e do seu desenvolvimento. Assim, ao discutirmos sobre os conhecimentos necessários a docência para o trabalho com a Linguagem Escrita, inferimos a discussão empreendida por Tardif 
(2014) sobre os diferentes saberes docentes que contribuem para a constituição do ensino como profissão e não meramente vocacional. A saber: os saberes da Formação Profissional, os saberes Disciplinares, Saberes Curriculares e os saberes da Experiência.

Nessa análise, sobre os saberes que contribuem para situar o trabalho docente, o ensino como, atividade profissional, ou seja, como ação consciente, situamos os saberes disciplinares. Tais saberes, estão relacionados aos diferentes campos de conhecimento e "[...] se encontram hoje integrados nas universidades sob a forma de disciplinas [...], por exemplo, (Matemática, História, Literatura, etc.)" (TARDIF, 2014, p.38). Com isso, assumimos que a promoção de situações de ensino de qualidade requer conhecimento sobre o objeto de estudo. É apenas um dos saberes, mas sem ele, não há como construir uma atuação profissional. Evidentemente, esse saber envolve conhecimentos teóricoprático, em sua organização.

Retomamos um dos argumentos de Lerner (2002) sobre a importância da definição dos saberes/conhecimentos fundamentais para situar a prática docente em relação ao ensino da leitura e a escrita. A referida autora evidencia que é fundamental o professor conhecer sobre o sujeito da aprendizagem (a criança, como aprende e se desenvolve), sobre o objeto de ensino (a linguagem escrita, o que é ler e escrever) e sobre as formas de organização do ensino (conhecimento didático, do ato de planejar, desenvolver e avaliar processos). Questões que desafiam a constituição da docência na Educação Infantil e, ao mesmo tempo, lançam luz sobre que saberes/conhecimentos precisam assumir centralidade na formação de professores, quando o objeto de conhecimento possui relação direta com a apropriação da Linguagem Escrita.

Estabelecer um repertório de conhecimentos mobilizados na prática profissional docente é fundamental para analisar os percursos de formação de professores e, ao mes mo tempo, suas necessidades formativas, sendo esta, uma das condições fundamentais para a profissionalização do ensino (GAUTHIER, 2013). Para esse autor, a não formalização dos saberes do professor produz uma espécie de cegueira conceitual propagando a ideia de que para ensinar basta conhecer o conteúdo, ter talento, experiência, cultura, bom senso ou simplesmente seguir a intuição. Ter um ofício sem saberes é tão reverberador da desprofissionalização quanto a existência de saberes sem ofício, que são aqueles que nunca são reexaminados à luz do fazer do professor (GAUTHIER, 2013).

Considerando essas questões, analisamos as ideias preconcebidas sobre o professor da Educação Infantil: "a tia", a "professorinha" da "escolinha", 
preferencialmente mulher que possui um sentimento materno, por isso, sendo doce e amável está "capacitada" para cuidar das crianças pequenas. Não seria tal preceito cegueira conceitual? Tal parecer traz à tona uma atividade professoral vocacionada que não se configuraria como uma atividade, enquanto ofício constituído de saberes.

Nessa perspectiva, trazemos os pressupostos da teoria Histórico-Cultural, buscando situar alguns saberes/conhecimentos necessários a uma ação docente capaz de promover a apropriação da linguagem escrita da criança pequena com sentido e significado. Sem a intenção de apresentar um modelo pronto e acabado, entendemos que algumas de suas contribuições oferecem elementos para fundamentar a ação educativa.

A prática docente é determinada por algumas questões dentre as quais destacamos, as concepções que o professor possui sobre a criança, sua aprendizagem e desenvolvimento, ampliando-as para uma dimensão mais ampla como concepções de educação, sobre as relações de ensino, sobre a sociedade e sobre os modos de ensinar e aprender dos sujeitos, dentre outras.

Assim a concepção de linguagem que o docente assume é crucial para orientar sua prática pedagógica. Esta concepção pode estar fundada em diferentes concepções, a saber: linguagem como expressão do pensamento, como instrumento de comunicação e, como interação. Assumimos, neste trabalho os pressupostos de uma concepção de linguagem como interação, a qual é defendida por Geraldi (2011) como sendo aquela que parte de uma compreensão de sujeito, de sociedade e de aprendizagem que são condizentes com os pressupostos que coadunam com a teoria Histórico-Cultural.

Esta concepção de linguagem como interação, subtende uma compreensão de linguagem escrita como processo responsivo e discursivo. Assim, sua apropriação ocorre por meio da interação e interlocução entre todos os envolvidos no processo (SMOLKA, 2012). Como sujeito ativo "a criança aprende a ouvir, a entender o outro pela leitura; aprende a falar, a dizer o que quer pela escrita” (SMOLKA, 2012, p. 87). Desta forma, a apropriação da linguagem escrita acontece em um processo em que a criança é concebida, sempre, como leitora e produtora de textos.

Diante do exposto, acreditamos que as questões discutidas a partir dos postulados teóricos aqui analisados, contribuem para uma prática docente, voltada às necessidades de aprendizagem das crianças. Configuram-se, como saberes necessários para organizar as situações de ensino com a linguagem escrita na Educação Infantil. Tem potencial de 
produzir reflexões potentes para os professores, desencadeando mudanças na forma como concebem a sociedade, o ser humano e próprio papel do educador (MELLO, 2010b).

Assim, a centralidade desse estudo reside no fato de que os pressupostos teóricos Histórico-Cultural, podem situar significativamente, os saberes/conhecimentos fundamentais aos professores da Educação Infantil. Acreditamos que as discussões a seguir são importantes para analisar um “corpus” de saberes/conhecimentos necessários ao professor da Educação Infantil que busca possibilitar o encontro das crianças com a linguagem escrita com sentido e significado.

Afinal, o que defende a teoria Histórico-cultural sobre esse processo de apropriação da linguagem escrita e que pode orientar o trabalho docente com esse objeto cultural? No próximo tópico, analisamos algumas concepções, a partir dessa teoria, as quais entendemos como sendo aqueles, pressupostos fundamentais, ou o ponto de partida para situar os saberes/conhecimentos básicos de professores da infância. Não temos a pretensão de esgotar essa discussão em um único trabalho, considerando as inúmeras contribuições produzidas nessa por esse viés teórico.

Nesse estudo evidenciamos o que é possível, ampliar e discutir sobre a ressignificação dos saberes/conhecimentos de professores da Educação Infantil, relativos a linguagem escrita. Segue o que chamamos de pressupostos de base para a prática docente.

\section{ALGUNS PRESSUPOSTOS SOBRE PROCESSO DE APROPRIAÇÃO DA LINGUAGEM ESCRITA}

Conforme mencionado anteriormente, nossa pretensão é promover uma reflexão e ampliação sobre os conhecimentos produzidos a partir das teorizações da abordagem Histórico-Cultural no que se refere a apropriação da linguagem escrita pela criança e de que forma tais conhecimentos podem subsidiar o trabalho dos professores da Educação Infantil. Defendemos a ideia de que "a teoria se concretiza em práticas intencionais quando temos procedimentos que a concretizem" e que "não há trabalho docente sem uma teoria que o fundamente" (PEDERIVA; COSTA; MELLO, 2017, p. 24).

A teoria Histórico-Cultural, emergiu na década de 1920, na antiga União Soviética, tendo como principal precursor o teórico Lev Semionovitch Vigotski (1896 1934). Suas bases filosóficas e educacionais fizeram emergir uma nova forma de conceber a criança, a aprendizagem e o desenvolvimento humano. Tais bases possibilitaram uma 
nova forma de conceber e propor os processos de ensino e aprendizagem. Produziram fundamentos para a compreensão da apropriação da linguagem, parti ndo do entendimento de que o foco central dessa apropriação é o desenvolvimento das capacidades humanas do sujeito, ou seja, do seu processo, de humanização. Portanto é nesse contexto que a linguagem escrita, assume um importante papel, que é o de contribuir com o processo de constituição da cidadania. Vygotsky (1995, p. 183) afirma que é por meio da apropriação da linguagem escrita, que ocorre o processo de "desenvolvimento cultural da criança".

Assim, a teoria Histórico-Cultural anuncia uma concepção de ser humano contrária àquelas que acreditam que a criança já nasce com um conjunto de aptidões que serão desenvolvidas ao longo da sua vida. Na verdade, assume como uma de suas teses centrais, de que o homem não nasce humano. Sua humanidade é externa a ele. "Desenvolve-se ao longo de um processo de apropriação da cultura que as novas gerações encontram ao nascer, acumulada pelas gerações precedentes [...]" (MELLO, 2016, p. 17). Desta forma, as características biológicas das crianças ao nascer não são suficientes ou a base para compreender o processo de desenvolvimento, das qualidades humanas e das funções psicológicas superiores. Na verdade, o desenvolvimento do sujeito de suas potencialidades ocorre, principalmente por meio das relações, com os seres humanos e com os objetos da cultura. (LEONTIEV, 1978).

Portanto, a linguagem escrita é considerada nesse contexto como objeto cultural, constituinte da formação humana. Tal postulado traz um novo entendimento do papel da educação para a constituição de uma sociedade mais humana já que este é impulsionado pelo aprendizado. Assim, a escola torna-se um dos espaços privilegiados para a aproximação da criança com a cultura, na sua forma mais elaborada, um contexto propício para o desenvolvimento das máximas potencialidades das crianças por meio de práticas intencionais. A criança, nessa perspectiva, deve ser concebida como sendo um ser social, histórico e cultural, que aprende participando ativamente do seu processo de aprendizagem e desenvolvimento. De acordo com Vigotsky (1996, p. 382) “[...] a criança é uma parte do meio e esse meio nunca é externo para ela. Se a criança é um ser social e seu meio é o meio social, [...] a própria criança é parte de seu meio social".

Ao conceber a criança como ser que interage desde o nascimento com o meio social e cultural, que aprende de forma ativa por meio da interação com o outro e sua cultura, a teoria Histórico-Cultural oferece elementos para a compreensão do processo de apropriação da linguagem escrita. É um ponto departida importante, pois evidencia 
modos próprios de pensar a aprendizagem e desenvolvimento da criança. Evidentemente, outras concepções serão esclarecidas ao longo desse trabalho. Temos a plena convicção de que ao compreendermos a concepção de criança, é possível situar o trabalho docente de professores da Educação Infantil com a linguagem escrita. Evidencia possibilidades de justificar suas escolhas metodológicas em sala de aula. Afinal, para ensinar efetivamente é fundamental ter clareza acerca dos sujeitos da aprendizagem, ou seja, como aprendem. A teoria aqui abordada contribui para situar essa relação de ensino, aprendizagem e desenvolvimento.

Outra questão importante, remete à compreensão da linguagem escrita como objeto cultural, com o qual a criança se relaciona antes mesmo de adentrar nas instituições de ensino. Essa compreensão requer que as práticas pedagógicas com a linguagem es crita na escola, sejam permeadas por atividades contextualizadas, mantendo a sua função e os seus usos sociais. Sobre essa questão, Luria (2001) evidencia o quanto é fundamental respeitar a história da criança e sua relação com esse objeto cultural. Destac a ainda que:

\begin{abstract}
A história da escrita na criança começa muito antes da primeira vez em que o professor coloca um lápis em sua mão e lhe mostra como formar letras. $\mathrm{O}$ momento em que uma criança começa a escrever seus primeiros exercícios escolares em seu caderno de anotações não é, na realidade, o primeiro estágio do desenvolvimento da escrita. [...] podemos até mesmo dizer que quando uma criança entra na escola, ela já adquiriu um patrimônio de habilidade e destrezas que a habilitará a aprender a escrever em um tempo relativamente curto. Se apenas pararmos para pensar na surpreendente rapidez com que uma criança aprende esta técnica extremamente complexa, que tem milhares de anos de cultura por traz de si, ficará evidente que isto só pode acontecer porque durante os primeiros anos de seu desenvolvimento, antes de atingir a idade escolar, a criança já aprendeu e assimilou um certo número de técnicas que prepara o caminho para a escrita. (LURIA, 2001, p. 143).
\end{abstract}

Podemos inferir, de acordo com as ideias que antes de entrar na escola, a criança está envolvida com um conjunto de experiências com a linguagem escrita à medida que se comunica, expressa seus sentimentos, nas relações sociais e no contato com diversos materiais escritos. Portanto, a partir desse pressuposto, é possível o professor orientar seu trabalho docente, considerando as vivências das crianças com a linguagem escrita anteriores a sua entrada na escola. Devem se perguntar: o que essa criança sabe/experienciou com a linguagem escrita e tem sentido para ela? Essa questão é um ponto de partida importante para nortear o processo de planejamento docente. Contribui para situar a concepção de criança e de linguagem e ao mesmo tempo orientar o processo 
de aprendizagem e desenvolvimento. Esses elementos são orientadores para o desenvolvimento de práticas significativas com as crianças.

Nesse contexto, Vygotsky (2007) critica a forma como a Linguagem Escrita, muitas vezes é apresentada para as crianças no espaço escolar. De acordo com o autor, esse processo é centrado nos aspectos formais e técnicos da língua. As atividades são permeadas por tarefas mecânicas, destituindo a linguagem escrita de sua função social. O autor destaca ainda, que a apropriação de um instrumento cultural tão complexo como a escrita, não pode acontecer de forma mecânica, nem espontânea. É preciso desenvolver situações, nas quais as crianças desenvolvam o seu desejo de expressão. Para tanto é fundamental que os professores compreendam o que é a escrita, o seja, como ocorre sua constituição. Nesse sentido, o autor esclarece que:

\begin{abstract}
A escrita é um sistema particular de símbolos e signos cuja dominação prenuncia um ponto crítico em todo o desenvolvimento cultural da criança. [...] constitui um simbolismo de segunda ordem que, gradualmente, torna-se um simbolismo direto. Isso significa que a linguagem escrita é constituída por um sistema de signos que designam os sons e as palavras da linguagem falada, os quais, por sua vez, são signos das relações e entidades reais. Gradualmente, esse elo intermediário (a linguagem falada) desaparece, e a linguagem escrita converte-se num sistema de signos que simboliza diretamente as entidades reais e as relações entre elas. (VYGOTSKY, 2007, p. 126).
\end{abstract}

Dessa forma, a escrita deve representar a realidade, ou seja, estabelecer uma relação com o mundo real e não apenas com os sons, letras e palavras isoladas. O conceito apresentado acima evidencia o sentido e o significado da escrita, ou seja, o que é a escrita? Os professores precisam se perguntar sobre essa questão. São essas concepções de criança, de aprendizagem e desenvolvimento, de linguagem e, por sua vez, de escrita, de leitura, que devem constituírem-se como base para organização da prática docente na Educação Infantil. Essa última concepção sobre o que é a escrita, deve ser situada na sua relação com a concepção de linguagem escrita. Nas palavras de Vygotsky (2007), somos provocados a desenvolver uma crítica consistente, aquelas situações de ensino que tomam como ponto de partida o trabalho com letras, sons, palavras e frases isoladas. Uma vez que dessa forma, estamos dificultando o processo de compreensão por parte das crianças, comprometendo a construção de sentido e significado.

É necessário, portanto, um longo processo de intervenção e de reflexão para que a criança perceba que esse instrumento da cultura representa uma realidade, a vida e, por isso, têm um sentido e um significado. Assim, é fundamental que os professores da 
infância se apropriem de conhecimentos/saberes que possam contribuir com a compreensão de como as crianças se apropriam da linguagem escrita, atribuindo sentido e significado a esse objeto cultural.

Para Vygotsky (2007), a compreensão da história do desenvolvimento dos signos na criança é fundamental para entendermos como ocorre esse processo. É indispensável entender a pré-história da escrita, atrelada à compreensão das concepções mencionadas anteriormente. É um ponto estratégico para os professores planejarem situações de ensino com a linguagem escrita. Essa compreensão, acerca da pré-história da escrita apresenta um percurso que revela como a criança vai construindo a sua relação com esse objeto. "[...] mostrar o que leva as crianças a escrever, mostrar os pontos importantes pelos quais passa o desenvolvimento pré-histórico e qual a sua relação com o aprendizado escolar" (VYGOTSKY, 2007, p. 127).

Corroborando com esta compreensão, Mello (2005, p. 27) afirma que a escrita na criança tem uma história a qual precisa ser considerada. A aquisição da escrita pela criança passa por uma trajetória que envolve:

[...] um longo processo de desenvolvimento das funções superiores do comportamento infantil que Vigotski chama de pré-história da linguagem escrita. Esta história - que é, na verdade, a história das formas de expressão da criança - é constituída por ligações em geral não perceptíveis à simples observação e começa com a escrita no ar, com o gesto da criança ao qual nós, adultos atribuímos um significado.

Esta concepção sobre o desenvolvimento da escrita na criança compreende que esta forma de expressão emerge a partir das possibilidades que as crianças possuem e das situações às quais são expostas. Inicia pela valorização de situações em que as crianças se expressam por meio do gesto, entedido como "[...] signo visual inicial que contém a futura escrita da criança [...]" (VYGOTSKY, 2007, p. 128), depois nos jogos de papéis, por meio da brincadeira do faz de conta, possibilitando que a criança se comunique, se expresse por meio dos jogos e brincadeiras que utiliza. “[...] a brincadeira do faz de conta é um importante instrumento que contribui para o desenvolvimento da escrita na criança - que é um sistema de simbolismo de segunda ordem”. (VYGOTSKY, 2007, p. 133).

Essa trajetória que apresenta o processo de construção, ou de significação da linguagem escrita por parte da criança, revela parte do seu desejo de expressão, que se manifesta, por meio da fala, do desenho e outros. Quando a criança utiliza essa linguagem gráfica, começa a expressar seu sentimento, atribui sentido para aquilo que faz e, assim, 
começa a representar a realidade. Vygotsky (2000, p.188, tradução nossa) diz que: no desenho das crianças há representações das partes e propriedades da realidade que teve contato. "O desenho desenvolve a capcidade de representar algo. A criança desenvolve a função de representação simbólica, tão importante para a aprendizagem da escrita”.

É neste percurso histórico que, a criança vai construindo, na relação com as diferentes formas de expressão, a compreensão sobre o que é a escrita, para que utilizamos esse objeto cultural. Nessa trajetória, a linguagem escrita vai se constituindo socialmente e forma as bases para futuramente as crianças compreenderem a escrita como uma atividade de expressão e de comunicação que se elabora e reelabora por meio de interações sociais.

Diante de nossas análises, é importante refletir sobre o papel do professor da Educação Infantil nesse contexto. Profissionais que tem como uma de suas funções principais a organização das situações de ensino e aprendizagem. Precisam constituíremse como sujeitos mais experientes, capazes de aproximar as crianças do conhecimento, de forma significativa, mediando a relação dessas crianças com os objetos da cultura, social e historicamente elaborados pela humanidade. Entretanto, esse processo ocorre somente quando a linguagem escrita é apresentada às crianças em contexto social e, portanto, real. Vygotsky (1995, p. 201) esclarece sobre essa questão afirmando que:

a criança deve sentir a necessidade de ler e escrever. [...]. Isso signific a que a escrita deve ter sentido para a criança, que deve ser provocada por necessidade natural, como uma tarefa vital que lhe seja imprescindível. Unicamente então, estaremos seguros de que se desenvolverá na criança não como um hábito de suas mãos e dedos, mas como um tipo realmente novo e complexo de linguagem.

Fica evidente, portanto, a necessidade de enfrentamento de concepções que centram suas práticas com a linguagem escrita, valorizando apenas, seus aspectos formais e técnicos, dando lugar àquelas concepções que valorizam a criança, seus modos de aprender e, sobretudo, a linguagem escrita como objeto cultural complexo. Esse objeto por sua vez, deve responder aos desejos e as necessidades das crianças. Assim é possível atribuírem sentido aos seus aprendizados. Mello (2005, p. 78) esclarece essa questão.

Dependendo da forma como apresentamos a escrita para as crianças, obstaculizamos a formação de um sentido seja adequado à escrita. $\mathrm{O}$ sentido que as crianças atribuirão à escrita será adequado se ele for coerente com a função social, coerente com o significado social da escrita. Podemos mostrar às crianças - por meio das vivências que 
proporcionamos envolvendo a linguagem escrita - que a escrita serve para escrever histórias e poemas, escrever cartas e bilhetes, registrar planos, intenções e acontecimentos, por exemplo [...] Assim, quando a criança atribui um sentido alienado à escrita (por exemplo, se ela entende que a escrita serve para juntar letras e fazer palavras), esse sentido dificulta sua utilização plena da escrita como comunicação e expressão de seus desejos de expressão, como a compreensão do desejo de expressão e comunicação das outras pessoas.

Aos professores da Educação Infantil cabe fazer um questionamento nesse momento, a saber: como apresentar a linguagem escrita para a criança de modo que possa atribuir sentido a esse objeto cultural? Como organizar/apresentar a escrita para as crianças em que a sua função social e os seus significados possam se constituir como elemento central do trabalho? A resposta a essas questões contribuem para situarmos quais saberes/conhecimentos os professores mobilizam em situações dessa natureza. Demandam por sua vez, a necessidade de saber/conhecer do ponto de vista teórico-prático sobre a escrita sua função social e seus significados.

O que precisa saber o professor da infância sobre a apropriação da linguagem escrita pela criança? Essas perguntas que aparecem ao longo do texto, são provocações para pensar sobre o que é possível responder com aquilo que se tem e, ao mesmo tempo, sinalizar o que ainda precisamos continuar estudando. Outras perguntas vão surgindo ao longo do trabalho, nessa perspectiva de, refletir sobre o que sabemos e o que precisamos aprofundar, sobre o tema em questão.

Nessa direção, Bakhtin (1986) ao refletir sobre o processo de apropriação da Linguagem Escrita, defende uma posição em que os textos ou gêneros do discurso assumam centralidade nas práticas com a linguagem escrita. $\mathrm{O}$ autor entende que a linguagem é um processo que ocorre nas relações entre os sujeitos a partir de necessidades reais. Os textos são gêneros que organizam nosso discurso, nossas necessidades de interação com o mundo e com a cultura. Defende ainda que as crianças devem "servir-se da língua para suas necessidades enunciativas concretas [...] num dado contexto concreto" (BAKHTIN, 1986, p. 92).

Entendendo a necessidade de expressão trazemos o texto, ou gêneros do discurso para essa análise como sendo uma das formas de expressão que a criança pode e deve fazer uso, desde a Educação Infantil. De acordo com Curto, Morillo e Texidó (1998), os textos organizam nossa fala, ou seja, processo de comunicação por meio da linguagem escrita. Portanto, colocar as crianças pequenas em contato com os textos em seus diferentes gêneros é também uma forma de oferecer condições para que se expressem, 
atribuindo, por sua vez, sentido à linguagem escrita. Os autores destacam que o trabalho com a linguagem escrita deve considerar os textos como unidade básica de sua organização e explicitam essa questão afirmando que:

“[...]. Se um texto é a unidade escrita com, significado e sentido próprios, somente por meio deles, a aprendizagem da linguagem escrita adquire significado e sentido. [...]. Todo trabalho com a linguagem escrita deve ser feito a partir de textos. Organizam toda a atividade escolar em linguagem escrita (CURTO; MORILLO; TEXIDÓ, 1998, p. 186).

Assim, o desafio é abordar a escrita sem destituí-la de seus usos sociais, e os textos contribuem para que as crianças compreendam o que, por quê e para quê, estão aprendendo esse objeto cultural - a linguagem escrita. Ao assumir o texto em contexto, como unidade de organização das práticas de linguagem emerge a necessidade de que os professores tenham clareza sobre o que são os textos, suas características, como e para que se organizam. Outra concepção que precisa fazer parte do processo de formação dos professores, são os saberes/conhecimentos relativos aos textos ou os gêneros discursivos ${ }^{4}$.

Nesse sentido, alguns questionamentos são importantes de serem elaborados nesse percurso de discussão, a saber: partir das contribuições de Vygotsky e colaboradores, como as crianças podem se expressar por meio da Linguagem Escrita de modo que atribuam sentido a esse processo? Como situar os gêneros do discurso, os textos - na organização desse trabalho com a Linguagem Escrita? Mais questionamentos para contribuir com a reflexão sobre o que sabemos e o que precisamos saber.

Dessa forma, apresentamos a seguir, o que definimos como uma síntese integradora a partir de alguns pressupostos da teoria Histórico-Cultural, analisados até então nesse trabalho, sobre o processo de apropriação da Linguagem Escrita. Essa síntese pode promover reflexões sobre esse objeto de conhecimento, com o intuito de fomentar uma atuação refletida e consciente acerca da prática docente dos profissionais da infância. Nesse sentido, buscamos responder uma questão central desse estudo: o que precisam saber os professores da Educação Infantil sobre o processo de apropriação da Linguage m Escrita? A seguir, elencamos as concepções que consideramos fundamentais e orientadoras das atividades de estudo e da prática docente de professores da Educação

\footnotetext{
${ }^{4}$ Conceito de gêneros discursivos em Bakthin " Os mais variados textos com aspectos discursivos, criados em contextos reais e por meio da interlocução verbal”.
} 
Infantil, em relação ao trabalho com a linguagem escrita. Quais pressupostos da teoria em questão, constituem-se como saberes/conhecimentos indispensáveis aos professores da Educação Infantil, sobre a linguagem escrita?

Saber/conhecer sobre a criança - A partir do aporte teórico desse estudo, a criança é considerada como ser social, histórico e cultural, portanto, sujeito que deve participar ativamente de todos os processos que dizem respeito a sua aprendizagem e desenvolvimento. É por meio da participação ativa, em situações reai s e contextualizadas que elaboram e reelaborama cultura. Cabe às instituições de Educação infantil, considerar a criança como sujeito capaz de aprender sempre, desde que as condições se constituam como sendo favoráveis a este processo. Que sejam respeitados seus modos próprios de aprender. Por isso, ao planejarmos situações de ensino, é preciso considerar que:

a criança possui ilimitada capacidade de aprendizagem, é capaz de ações humanizadoras, de relacionamentos, de convivências [...] constituindo sua natureza social humana, mediante apropriações e objetivações motivadoras de seu desenvolvimento cultural (LIMA; SILVA; RIBEIRO, 2010, p. 16).

Portanto, compreender a concepção de criança a partir de alguns pressupostos da teoria Histórico-Cultural, envolve o reconhecimento de que é fundamental situá-la como sujeito com potencialidades máximas, as quais precisam de condições apropriadas para o seu desenvolvimento. Cabe ao professor entender que apropriar-se dessa concepção é construir as bases para que sejam construídas possíveis trajetórias de organização das aprendizagens das crianças com a linguagem escrita.

Saber/conhecer sobre o processo de aprendizagem e desenvolvimento - A aprendizagem não ocorre por meio de atos mecânicos. Para Vygotsky (1988) é preciso considerar o desenvolvimento humano a partir do que denominou de Zona de desenvolvimento real, que diz respeito ao nível de desenvolvimento no qual a criança é capaz de realizar algo sozinha e, ao mesmo tempo, a relação deste processo com outro nível, que denominou de Zona de Desenvolvimento Proximal (ZDP), o qual é definido como sendo o nível de desenvolvimento no qual a criança pode realizar ações com a colaboração de um parceiro mais experiente. É na relação com esse parceiro que aos poucos a criança vai construindo as bases para realização de determinadas atividades sozinha. Assim, para ensinar, cabe ao professor compreender esses níveis de desenvolvimento, os quais as crianças vivenciam. Organizar a aprendizagem da criança, 
exige do professor uma atuação consciente. Portanto saber/conhecer sobre esse processo de desenvolvimento humano é fundamental.

Segundo Vygotsky a interação e as condições reais do sujeito são fundamentais para o processo de aprendizagem que, por sua vez, promove o desenvolvimento. Nesse processo, a cultura é uma das principais influenciadoras para o desenvolvimento mental estabelecendo as relações entre o contexto externo e interno do sujeito. Vygotsky (1982) afirma que o contexto social é fundamental no processo de desenvolvimento humano, tendo em vista que por meio das relações e interações o sujeito aprende e se desenvolve, a partir da observação e de experiências com o outro, com o mundo e sua cultura. Assim, os sujeitos aprendem quando estão em atividade, ou seja, o seu processo de aprendizagem e desenvolvimento relacionam-se com as condições reais. Planejar é condição fundamental para que as crianças tenham a oportunidade de aprender. Esse planejamento deve considerar a criança como sujeito da aprendizagem e a linguagem como objeto cultural, o qual contribui para o pleno desenvolvimento das potencialidades humanas e das funções psicológicas superiores.

As contribuições teóricas da abordagem Histórico-Cultural são de fato importantes para organizar a aprendizagem na escola. Afinal, como organizar o ato de ensinar sem considerar quem são as crianças e como ocorre seu processo de aprendizagem e desenvolvimento? E sobre as questões ou contribuições da teoria Histórico-Cultural em relação a linguagem escrita, analisar-se-á em seguida.

Saber/conhecer sobre linguagem escrita e sua apropriação - Mikhail Bakhtin/Volochínov, na obra Marxismo e Filosofia da Linguagem, defende a concepção de linguagem como Interação, pois considera o ser humano em seu contexto social e cultural. Evidencia que a atividade humana se organiza e se concretiza por meio da linguagem. Dorettto e Beloti (2011, p. 97), analisando a concepção de linguagem a partir das contribuições de Bakthin, ressaltam alguns aspectos importantes sobre a questão.

a linguagem é vista como processo de interação, a língua é usada não apenas para a comunicação, mas, também, para estabelecer a interação social (agir sobre, agir entre). O indivíduo realiza ações, atua sobre o interlocutor. Considera-se os contextos social, histórico e ideológico. "A linguagem é pois um lugar de interação humana, de interação comunicativa pela produção de efeitos de sentidos entre interlocutores, em uma dada situação de comunicação e em um contexto sóciohistórico e ideológico" (TRAVAGLIA, 1996, p. 23). Logo, a língua não deixa de ser expressão e comunicação, mas, além disso, passa a ser uma atividade sociointerativa. 
Assim, a concepção de linguagem assumida neste trabalho, é parte importante do conjunto de saberes/conhecimentos que os professores da Educação Infantil precisam compreender. Essa concepção interfere diretamente na organização do trabalho docente com as crianças. Portanto a linguagem como interação constitui-se na relação entre o linguístico e o discursivo, considerando os sujeitos da aprendizagem como sociais e historicamente situados, constituídos dessa forma, pela linguagem.

Apresentamos alguns dos pressupostos que podem contribuir com uma prática consciente dos professores da Educação Infantil. Entendemos que podem e devem ser ampliados, considerando todos os postulados teóricos produzidos pela teoria HistóricoCultural. Aqui, apresentamos de forma sintética o que consideramos conhecimentos/saberes de base, ou ponto de partida para situar o trabalho docente nesse contexto, a saber: as concepções de criança, aprendizagem e desenvolvimento e linguagem escrita. Acreditamos que por meio do conhecimento teórico na sua relação com a prática é possível construir práticas de ensino referentes a linguagem com sentido e significado para as crianças. Concordando com as palavras de Possenti (1996) ao afirmar que não se aprende por meio de exercícios repetitivos, mas por meio de práticas significativas em contexto real.

Assim, a linguagem escrita não se constitui como sendo, um conjunto de signos que tem como foco a relação entre letras e sons. Na verdade, é um instrumento vivo em que a centralidade de sua organização está na construção de sentido e significado, tendo como unidade básica de sua organização, o texto em contexto. Por meio dos textos podemos nos expressar e desenvolver as condições para que as crianças desenvolvam o seu desejo de expressão.

Assim, o texto é a materialidade dos discursos, da interlocução verbal entre crianças e adultos, as quais incluem diferentes formas, características, funções e situações reais de uso. De acordo com Jolibert (2006), é fundamental no processo de escolha dos texto partir de situações reais. Não devemos escolher um texto considerando que o trabalho com o mesmo, ocorra apenas em seus aspectos organizacionais e técnicos, mas antes de tudo, é fundamental refletir sobre a situação real, na qual esse texto é utilizado na vida. Ou seja, para cada situação um texto, e para cada texto, é importante que os professores conheçam sobre suas características, função e seus usos.

O processo de aprendizagem e desenvolvimento das crianças, sobretudo em relação a sua apropriação da linguagem escrita, demanda um longo processo de 
intervenção dos professores, assumindo o papel de sujeitos mais experientes. Sujeitos que organizam situações de aprendizagem com a linguagem escrita, com foco na sua dimensão cultural e social.

Portanto é preciso garantir aos professores espaços de formação, nos quais a linguagem escrita e, o seu processo de apropriação por parte da criança, possam constituírem-se como conteúdos centrais desses espaços formativos. Para tanto, alguns dos pressupostos da Teoria Histórico-Cultural abordados neste trabalho, são essenciais para pensar em perspectivas e de ressiginificação de práticas. De certo que essa discussão não se esgota neste estudo. Há muito mais a ser dito, analisado sobre esse processo.

\section{CONSIDERAÇÕES FINAIS}

Analisar a produção Vygotskyana para compreender o processo de apropriação da linguagem escrita pela criança na Educação Infantil, nos remete a uma reflexão sobre o que é necessário que os professores conheçam e, ao mesmo tempo, promover uma reflexão sobre a necessidade de transformação nas práticas pedagógicas escolares.

Os saberes docentes vêm sendo discutidos nas pesquisas em educação nos âmbitos nacionais e internacionais trazendo a importante questão da necessária profissionalização docente. Assim, entendemos que cada vez que problematizamos temáticas sobre a forma como as crianças aprendem e ao mesmo tempo, sobre objetos de aprendizagem, como a linguagem escrita é fundamental situar os conhecimentos que servirão de base para o professor acessar e tomar como ponto de partida para organização do seu trabalho.

Não há dúvidas de que uma prática consubstanciada em um referencial teórico consistente é essencial para uma atuação profissional de qualidade. O movimento proposto é capaz de evidenciar uma prática docente fundamentada em uma teoria em que o ensino, visto como ofício, é capaz de mover o professor em direção à necessidade de continuar estudando, buscando novos modos de pensar e trabalhar com as crianças.

Diante do esboço teórico apresentado, derivamos conclusões a partir dos pressupostos da teoria Histórico-Cultural e sua contribuição para a apropriação da linguagem escrita das crianças pequenas nos espaços de Educação Infantil. Desse modo, enquanto saber indispensável, a base teórica que aqui discutimos, oferece-nos a possibilidade de organizar o ensino, de modo que as crianças se apropriem da escrita enquanto uma linguagem complexa e necessária. Reafirmamos, também, que o processo 
de apropriação da linguagem escrita pela criança, se dá no percurso de um longo caminho, onde o professor assume uma importante posição, o de mediador/a na organização do trabalho pedagógico e provocador do desejo de expressão da criança.

Diante de perspectivas que foram se constituindo ao longo da história na educação das crianças pequenas, temos o grande desafio de enfrentar práticas pedagógicas destituídas de sentido e significado para as crianças, que focam o trabalho com a linguagem escrita, valorizando seus aspectos técnicos. Sabemos que tais práticas não contribuem para o desenvolvimento da necessidade de ler e de escrever.

O referencial teórico que assumimos nesse trabalho, apresenta possibilidades para ampliar os conhecimentos sobre a criança, seu processo de aprendizagem e desenvolvimento e por sua vez, sobre a linguagem escrita. Nesse sentido essas, concepções foram tratadas como saberes/conhecimentos indispensáveis à reorganização da prática docente, especialmente por contribuir para o desenvolvimento das máximas capacidades humanas das crianças.

Nessa perspectiva, é possível analisar a função do professor da Educação Infantil, afirmando que constitui-se como sendo um ofício feito de saberes. Não é possível promover a apropriação da linguagem escrita na Educação Infantil sem que haja uma tomada de consciência sobre o que é necessário o professor saber/conhecer.

Reiteramos que a compreensão sobre a criança, a linguagem e sua apropriação requer dos educadores um logo caminho de estudos sobre as as variáveis que interferem nesse processo. Cabe às instituições formadoras, garantirem formação e acesso de professores nessa direção. Aos professores, cabe utilizarem como investigações, o seu trabalho para validar o que estão fazendo ressignificando quando for necessário.

A questão central do trabalho, foi evidenciar que toda prática docente torna-se, consciente/consistente e, portanto profissional, quando as concepções que norteiam o trabalho docente estão claras para o professor. Este foi o nosso desafio, apresentar a partir da teoria Histórico-Cultural, bases para compreensão de algumas das concepções que servem de sustentação para alicerçar o trabalho com a linguagem escrita. A concepção de criança, de aprendizagem e desenvolvimento, de linguagem escrita, de texto e de Educação Infantil, são as bases com as quais os professores organizam suas práticas, ainda que não tenham consciência disto. Por isso, garantir aos professores dessa etapa espaços de formação de qualidade, os quais tematizaem essas concepções, para uma articulação 
teorico-prática é uma das condições fundamentais para construção de uma docência na educação Infantil, reconhecida como profissão, como ofício constituído de saberes.

\section{REFERÊNCIAS}

ARCE, A. Documentação oficial e o mito da educadora nata na Educação Infantil.

Caderno de Pesquisa, n. 113. p. 167-184, jul. 2001. Disponível

em: $<$ https://www.scielo.br/j/cp/a/KBkSjzMqRzJYD493bKxwVVw/?lang=pt\& format=p df>. Acesso em: 07 out. 2021.

BAKHTIN, M. Marxismo e filosofia da linguagem: problemas fundamentais do método sociológico na ciência da linguagem. São Paulo: Hucitec, 1986.

DORETTO, S. A.; BELOTI, A. Concepções de linguagem e conceitos correlatos: a influência no trato da língua e da linguagem. Revista Encontros de Vista, Universidade Federal Rural de Pernambuco, v. 8, p. 89-103, jul./dez. 201. Disponível em: $\lfloor$ http://journals.ufrpe.br/index.php/encontrosdevista/article/view/4470/482484192 >. Acesso em: 07 out. 2021.

GAUTHIER, C. et al. Por uma teoria da pedagogia: pesquisas sobre o saber docente. 3. ed. Ijuí: Ed. Unijuí, 2013.

GERALDI, J. W. Concepções de linguagem e ensino de português. In: O texto na sala de aula. Cascavel: Assoeste, 2011.

LEONTIEV, A. N. O desenvolvimento do psiquismo. Lisboa: Livros Horizonte, 1978.

LERNER, D. Ler e escreverna escola - O real, o possível e o necessário. Porto Alegre: Artmed, 2002.

LIMA, E. A. de; SILVA, A. L. R. da; RIBEIRO, A. E. M. Reflexões sobre a educação infantil: contribuições da teoria histórico-cultural. Revista Interfaces, ano 2, n. 2, p. 1620, out., 2010. Disponível

em: $<$ http://uniesp.edu.br/sites/_biblioteca/revistas/20170419175125.pdf $>$. Acesso em: 07 out. 2021.

LURIA, A. R. O desenvolvimento da escrita na criança. In: LURIA, A. R.; LEONTIEV, A. N.; VYGOTSKY, L. S. Linguagem, desenvolvimento e aprendizagem. São Paulo: Ícone Editora, 2001.

MARKONI, M. de A.; LAKATOS, E. M. Fundamentos de Metodologia Científica. 7. ed. São Paulo: Atlas, 2010.

MELLO, S. A. O processo de aquisição da escrita na educação infantil: contribuições de Vigotsky. In: FARIA, A. L. G.; MELLO, S. A. (Orgs.). Linguagens infantis: outras formas de leitura. Campinas: Autores Associados, 2005, p. 23-40.

MELLO, S. A. A Apropriação da Escrita como Instrumento Cultural Complexo. In: MENDONÇA, S. G. de L.; MILLER, S. (Orgs). Vigotski e a Escola Atual: fundamentos 
teóricos e implicações pedagógicas. 2. ed. - Araraquara: J.M. Editora e Cultura Acadêmica Editora, 2010a.

MELLO, S. A. Ensinar e Aprender a Linguagem Escrita na Perspectiva HistóricoCultural. In: Psicologia Política. v. 10. n. 20. p. 329-343. jul. dez. 2010b. Disponível em: <http://pepsic.bvsalud.org/pdf/rpp/v10n20/v10n20a11.pdf >. Acesso em: 07 out. 2021.

MELLO, S. A. Algumas implicações pedagógicas da Escola de Vygotsky para a educação infantil. Pro-Posições, Campinas, SP, v. 10, n. 1, p. 16-27, 2016. Disponível em: <https://periodicos.sbu.unicamp.br/ojs/index.php/proposic/article/view/8644097>.

Acesso em: 27 jan. 2021.

MELLO, S. A. Letramento e alfabetização na Educação Infantil, ou melhor, formação da atitude leitora e produtora de textos nas crianças pequenas. In: Educação infantil e sociedade: questões contemporâneas. VAZ, A. F; MOMM, C. M. (Orgs.). Nova Petrópolis: Nova Harmonia, 2012.

PEDERIVA, P. L. M.; COSTA, S. A. da; MELLO, S. A. Uma teoria para orientar nosso pensar e agir docentes na educação infantil. In: COSTA, S. A. da; MELLO, S. A (Orgs.). Teoria Histórico-Cultural na Educação Infantil: conversando com professoras e professores. 1. ed. - CRV, Curitiba - PR, 2017, p. 11-24.

SMOLKA, A. L. B. A criança na fase inicial da escrita: a alfabetização como processo discursivo. São Paulo: Cortez, 2012.

TARDIF, M. Saberes profissionais dos professores e conhecimentos universitários: elementos para uma epistemologia da prática profissional dos professores e suas consequências em relação à formação para o magistério. Revista Brasileira de Educação, jan-abr, v. 3, n. 13, p. 5-24, 2000. Disponível em:< http://anped.tempsite.ws/novo portal/rbe/rbedigital/RBDE13/RBDE13 05 MAURICE TARDIF.pdf>. Acesso em: 07 out. 2021.

TARDIF, M. Saberes docentes e formação profissional. 16. ed. Petrópolis, RJ: Editora Vozes, 2014.

TARDIF, M.; LESSARD, C. O trabalho docente: elementos para uma teoria da docência como profissão de interações humanas. 6. ed. Petrópolis: Vozes, 2011.

VYGOTSKY, L. S. (1995). La Pre historia del Desarrollo del Lenguaje Escrito. In: VYGOTSKY, L. S. Obras Escogidas III. Madrid: Visor (Original Publicado em 1960).

VYGOTSKY, L. S. Aprendizagem e desenvolvimento na idade escolar. In: VIGOTSKI, L. S.; LURIA, A. R.; LEONTIEV, A. N. Linguagem, Desenvolvimento e Aprendizagem. São Paulo, Ícone: Edusp, 1988, p. 103.

VYGOTSKY, L. S. Problemas de la Psicologia. Obras escogidas - Tomo IV. Madrid: Machado Libros, 1996. p. 249-386. 
VYGOTSKY, L. S. A pré-história do desenvolvimento da linguagem escrita. In: Obras escogidas. 2. ed. Madrid. Visor, 2000. p. 183-206.

VYGOTSKY, L. S. A formação social da mente. 7. ed. Trad. José Cipolla Neto e outros. São Paulo: Martins Fontes, 2007.

Recebido em: 01/09/2021

Aprovado em: 21/09/2021

Publicado em: 30/09/2021 